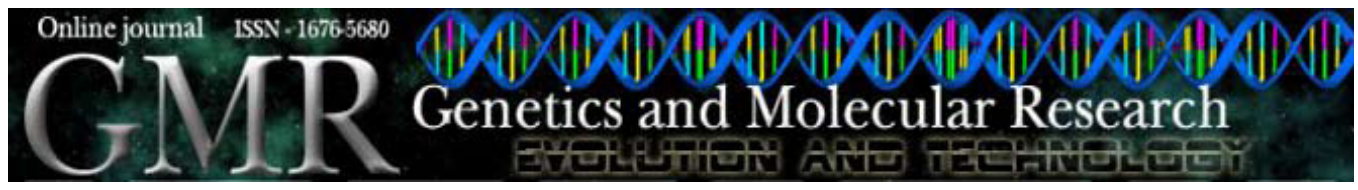

\title{
Cytogenetic and molecular analysis of an apomictic cassava hybrid and its progeny
}

\author{
N.M.A. Nassar ${ }^{1}$, P.T.C. Gomes ${ }^{1}$, A.M. Chaib ${ }^{1}$, N.N. Bomfim ${ }^{1}$, \\ R.C.D. Batista ${ }^{1}$ and R.G. Collevatti ${ }^{2}$ \\ ${ }^{1}$ Departamento de Genética e Morfologia, Universidade de Brasília, \\ Brasília, DF, Brasil \\ ${ }^{2}$ Departamento de Biologia Geral, Instituto de Ciências Biológicas, \\ Universidade Federal de Goiás, GO, Brasil \\ Corresponding author: N.M.A. Nassar \\ E-mail: nagnassa@rudah.com.br
}

Genet. Mol. Res. 8 (4): 1323-1330 (2009)

Received August 17, 2009

Accepted September 2, 2009

Published November 3, 2009

\begin{abstract}
An interspecific hybrid between cassava and Manihot glaziovii acquired an apomixis gene from the parent M. glaziovii. This hybrid was exposed to open pollination during three subsequent generations. Seven sibs and the maternal progenitor of the fourth generation were genotyped using six microsatellite loci previously developed for cassava. All sibs were identical with each other and with their maternal progenitor. Sibs of selfed M. glaziovii proved to be identical when examined with these microsatellite loci. The chromosome complement of the apomictic clone was $2 \mathrm{n}=38$. We observed multi-embryonic aposporic embryo sacs.
\end{abstract}

Key words: Interspecific hybrid; Apomixis; Aneuploidy; Wild species 


\section{INTRODUCTION}

Cassava is the most important staple crop in the humid tropics and a food for more than 800 million people (FAO, 2001). Apomixis is the asexual production of seed, and apomictic plants are clones of their mothers. It preserves heterosis and maintains superior varieties without genetic segregation. In cassava, propagation is normally by cuttings, which accumulate bacteria and viruses year after year, causing deterioration of productivity. The use of seeds in the propagation of this crop should avoid this disadvantage. Thus, an advantage of introducing apomixis in cultivated cassava is that it will assure preservation of superior clones since new emerging stems through apomixis will be free from viruses and bacteria. If apomixis had been found or had been introduced into excellent Brazilian clones, such as guaxupe and vassourinha, they would have been preserved for a long time. Apomixis could also benefit international centers that export their germplasm routinely, as a destination country needs only to raise one plant and further propagate it vegetatively to maintain its superiority.

In an earlier work of the first author, apomixis was discovered in the wild cassava Manihot glaziovii. Since this species is characterized by resistance to both mealy bug and bacterial blight, it was planned to transfer genes for apomixis as well as resistance to mealy bug and bacterial blight by interspecific hybridization.

In 1996, hybrids between cassava and the wild species M. glaziovii were obtained by the first author. The detection of aposporic embryo formation by a clearing method showed apomixis in these hybrids. Details of this method can be found elsewhere (Nassar, 2001, 2007; Nassar et al., 2000, 2008). The hybrid, however, formed fibrous roots, which impede its utilization for human consumption. It was allowed to open-pollinate among a population of cassava. Its progeny was then examined for apomixis embryologically and all the sibs but one showed apomixis and sterility. The only plant that showed fertility had its seeds grown to form a progeny of 22 sibs. These plants were examined embryologically by the first author in 2000. One of these plants proved to be aposporic (clone 307). It was allowed to open-pollinate and then to form fruit, and seven plants from its progeny were raised in 2002 for genetic analysis to confirm apomixis.

Microsatellite (simple sequence repeats) are co-dominant multiallelic markers that usually display high levels of polymorphism. They can be used to explore the presence of heterozygosity and/or identity (Morgante and Olivieri, 1993). Because of that, microsatellites are one of the most powerful molecular markers to understand detailed patterns of parentage composition and for individual discrimination in clone identification (e.g., Dayanandan et al., 1998; Vignani et al., 2002; Bekkaoui et al., 2003; James et al., 2003; Wyman et al., 2003). Additionally, microsatellite primers may be transferred between closely related species because of the homology of flanking regions of simple sequence repeats.

In this report, we present the results of microsatellite screening of plant clone 307 (see Appendix) and its progeny, and of the original progenitor plant $M$. glaziovii to confirm the occurrence of apomixis. We also present results of a cytogenetic and histological study.

\section{MATERIAL AND METHODS}

For the genetic analysis of the mother plants, clone 307 and M. glaziovii, and their progeny (seven sibs each), expanded leaves were collected and stored at $-80^{\circ} \mathrm{C}$. Additionally, two individuals of M. esculenta were collected for an amplification control. Genomic DNA 
was extracted following a standard CTAB procedure (Doyle and Doyle, 1990).

Twelve microsatellite loci previously developed for M. esculenta (Chavarriaga-Aguirre et al., 1998) were tested for transferability to clone 307 and to M. glaziovii to perform the genetic analysis: GAGG-5, GA-12, GA-6, GA-21, GA-57, GA-126, GA-127, GA-131, GA-134, GA136, GA-140, GA-161. To test this, DNA from the mother plants (clone 307 and M. glaziovii) and two sibs from each progeny array were used. Additionally, DNA from two individuals of $M$. esculenta was used as positive control. Microsatellite amplifications were performed in a $15-\mu \mathrm{L}$ volume containing $0.3 \mu \mathrm{M}$ of each primer, $1 \mathrm{U}$ Taq DNA polymerase (Phoneutria, Brazil), 250 $\mu \mathrm{M}$ of each dNTP, $1 \mathrm{X}$ reaction buffer $(10 \mathrm{mM}$ Tris- $\mathrm{HCl}, \mathrm{pH} 8.3,50 \mathrm{mM} \mathrm{KCl}, 1.5 \mathrm{mM} \mathrm{MgCl}$ ), $0.25 \mathrm{mg}$ BSA and $10.0 \mathrm{ng}$ template DNA. Amplifications were performed using a Gene Amp PCR System 9700 (Applied Biosystems, USA) with the following conditions: $96^{\circ} \mathrm{C}$ for $2 \min (1$ cycle), and 30 cycles of $94^{\circ} \mathrm{C}$ for $1 \mathrm{~min}, 45^{\circ}$ or $55^{\circ} \mathrm{C}$ for $1 \mathrm{~min}$ (according to each locus), and $72^{\circ} \mathrm{C}$ for 1 $\mathrm{min}$, plus a final elongation of $72^{\circ} \mathrm{C}$ for $10 \mathrm{~min}(1 \mathrm{cycle})$. The amplified products were separated on $4 \%$ denaturing polyacrylamide gels stained with silver nitrate (Bassam et al., 1991) and sized by comparison to a 10-bp DNA ladder standard (Invitrogen, USA).

Those primers that amplified clear and interpretable products were used in our study. For this, the DNA of all individuals was amplified using the same polymerase chain reaction conditions described above and fragments were visualized again on $4 \%$ denaturing polyacrylamide gels stained with silver nitrate (Bassam et al., 1991) and sized by comparison to a 10-bp DNA ladder standard (Invitrogen).

For each locus, the number of alleles and expected and observed heterozygosities under Hardy-Weinberg equilibrium were estimated (Nei, 1978). Other analysis of departure from Hardy-Weinberg, probability exclusion of the first and second parents and assignment test (Marshall et al., 1998) could not be performed because all sibs but one individual from the $M$. glaziovii progeny array showed the same genotype as the mother plant. For the same reason, it was not possible to estimate the likelihood of observing at least identical multilocus genotypes by simulation (Stenberg et al., 2003). The probability of genetic identity (Paetkau et al., 1995) and the probability of two random individuals displaying the same genotype were obtained for each locus and overall loci in two ways. First, considering that the progeny array was obtained from an open-pollinated population (without genetic drift such that mutation allele frequency should be maintained between generations), we would expect the frequency of all alleles in the population to be $\mathrm{P}=0.25$, if the first parents were heterozygous for all loci. This method may represent a maximum value that should be obtained if all alleles showed the same frequency in the population $(P=0.25)$. Second, in each generation mother plants were pollinated in a cassava living collection population; thus, we estimated the probability using the allele frequency obtained by Elias et al. (2001) from a genetic diversity study of 290 individuals from 29 varieties of M. esculenta. Although this method does not estimate the probability for the population of cassava used in the study, we obtained an expected value for the battery of loci developed for M. esculenta.

A cytologic study was carried out on individuals of the 307 progeny to examine their meiotic behavior. Flower buds were fixed in acetic acid alcohol (3:1) for $24 \mathrm{~h}$, preserved in $70 \%$ ethanol, smeared and stained with $1 \%$ acetocarmin. For the embryo sac analysis in these individuals, unpollinated pistillate buds were collected $2 \mathrm{~h}$ before anthesis, fixed in acetic acid-alcohol and dissected. Ovules were dehydrated and cleared overnight in Herr's fluid (Young et al., 1979). Transparent ovules were then observed using a differentiation interphase contrast microscope. 


\section{RESULTS}

From the 12 microsatellite loci tested, five (GA12, GA13, GA16, GA21, GA126) and six (GA12, GA13, GA16, GA21, GA126, and GA131) amplified for 307 and for $M$. glaziovii, respectively. The two individuals of M. esculenta (positive control) showed clear amplification for all loci. For the five loci used for clone 307 and its progeny array, both individuals of $M$. esculenta showed the same genotype as them. For GA131, both displayed the genotype 98/116 bp, different from M. glaziovii (116/116).

All loci showed just one allele for the mother plant 307 and its progeny (Table 1). Thus, the difference between the observed and expected heterozygosity, and the probability of exclusion of first and second parents were equal to zero. For M. glaziovii and its progeny, loci GA21 and GA126 showed two alleles and just one allele, respectively (Table 2). For GA21, just one individual was heterozygous (GF25), and the difference between the observed and expected heterozygosity was 0.125 . For GA126 all individuals were heterozygous, and observed and expected heterozygosity were 1.000 and 0.533 , respectively. Hence, the probability of exclusion of first and second parents for the battery of loci was very low $(0.131008$ and 0.232318 , respectively). The probability of genetic identity $(I)$, considering equal frequency for all alleles in all loci $(\mathrm{P}=0.25)$, was $I=0.1094$ for each locus, and combined probability was $I C=1.56527 .10^{-5}$, for the five loci used for 307 and its progeny array, and $I C=1.71202 .10^{-6}$ for the six loci used for M. glaziovii and its progeny array. Considering the allele frequency obtained by Elias et al. (2001), genetic identity could be determined only for four loci: GA12 $(I=0.2833)$, GA21 $(I=0.4129)$, GA126 $(I=0.1437)$, and GA131 $(I=0.1684)$, resulting in a combined probability of $I C=2.85124 .10^{-3}$.

\begin{tabular}{|c|c|c|c|c|c|}
\hline Individual & GA12 & GA13 & GA16 & GA21 & GA126 \\
\hline $307 / \mathrm{M}$ & $140 / 140$ & $140 / 140$ & $104 / 104$ & $114 / 114$ & $180 / 180$ \\
\hline $307 / 2$ & $140 / 140$ & $140 / 140$ & $104 / 104$ & $114 / 114$ & $180 / 180$ \\
\hline $307 / 3$ & $140 / 140$ & $140 / 140$ & $104 / 104$ & $114 / 114$ & $180 / 180$ \\
\hline $307 / 4$ & $140 / 140$ & $140 / 140$ & $104 / 104$ & $114 / 114$ & $180 / 180$ \\
\hline $307 / 5$ & $140 / 140$ & $140 / 140$ & $104 / 104$ & $114 / 114$ & $180 / 180$ \\
\hline $307 / 6$ & $140 / 140$ & $140 / 140$ & $104 / 104$ & $114 / 114$ & $180 / 180$ \\
\hline $307 / 8$ & $140 / 140$ & $140 / 140$ & $104 / 104$ & $114 / 114$ & $180 / 180$ \\
\hline $307 / 9$ & $140 / 140$ & $140 / 140$ & $104 / 104$ & $114 / 114$ & $180 / 180$ \\
\hline
\end{tabular}

$307 / \mathrm{M}=$ clone 307 - mother plant; 307/2 to $307 / 9$ = progeny; allele size in base pairs.

\begin{tabular}{|c|c|c|c|c|c|c|}
\hline Individual & GA12 & GA13 & GA16 & GA21 & GA126 & GA131 \\
\hline $\mathrm{G} / \mathrm{M}$ & $140 / 140$ & $140 / 140$ & $104 / 104$ & $114 / 114$ & $176 / 206$ & $116 / 116$ \\
\hline $\mathrm{G} / 24$ & $140 / 140$ & $140 / 140$ & $104 / 104$ & $114 / 114$ & $176 / 206$ & $116 / 116$ \\
\hline $\mathrm{G} / 25$ & $140 / 140$ & $140 / 140$ & $104 / 104$ & $110 / 114$ & $176 / 206$ & $116 / 116$ \\
\hline $\mathrm{G} / 26$ & $140 / 140$ & $140 / 140$ & $104 / 104$ & $114 / 114$ & $176 / 206$ & $116 / 116$ \\
\hline $\mathrm{G} / 29$ & $140 / 140$ & $140 / 140$ & $104 / 104$ & $114 / 114$ & $176 / 206$ & $116 / 116$ \\
\hline $\mathrm{G} / 30$ & $140 / 140$ & $140 / 140$ & $104 / 104$ & $114 / 114$ & $176 / 206$ & $116 / 116$ \\
\hline $\mathrm{G} / 31$ & $140 / 140$ & $140 / 140$ & $104 / 104$ & $114 / 114$ & $176 / 206$ & $116 / 116$ \\
\hline $\mathrm{G} / 32$ & $140 / 140$ & $140 / 140$ & $104 / 104$ & $114 / 114$ & $176 / 206$ & $116 / 116$ \\
\hline
\end{tabular}

$\mathrm{G} / \mathrm{M}=$ M. glaziovii mother plant; $\mathrm{G} / 24$ to $\mathrm{G} / 32$ = progeny; allele size in base pairs. 


\section{DISCUSSION}

Our results indicate that all progeny of clone 307 may be the outcome of apomixis because all sibs showed the same genotype as the mother for the five loci examined (Table 1, Figure 1). Apomixis can be inferred for M. glaziovii as well, since only one sib showed a different genotype from the mother plant (Table 2, Figure 1), which appears to be the result of cross-pollination.

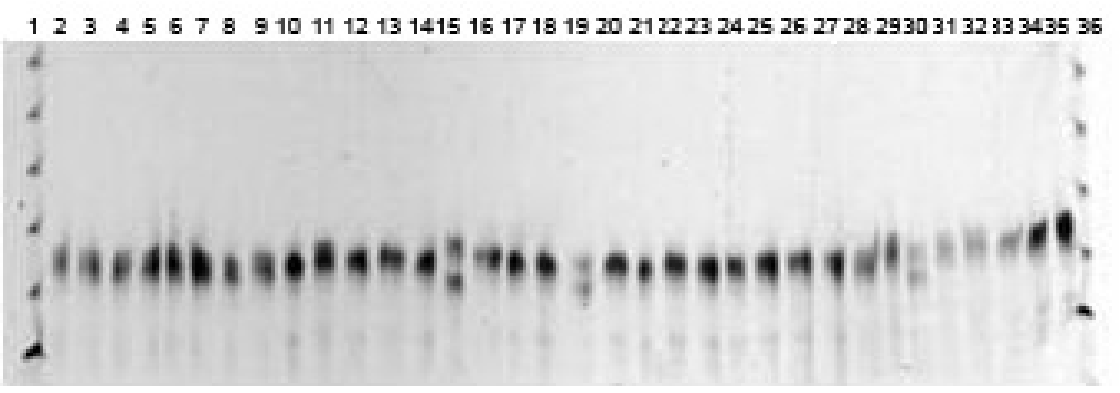

Figure 1. Genotype of clone 307 and Manihot glaziovii, and their progeny for locus GA21, visualized in silverstained denaturing polyacrylamide gel. Lanes 1 and 36 are 10-bp DNA ladder standards (Invitrogen). Lanes 2 and 3 are positive controls (M. esculenta). Lanes 4 to 11 are the hybrid and its progeny array. Lanes 28 to 35 are $M$. glaziovii and its progeny.

Considering that all progeny were submitted to open pollination in each generation, the low number of alleles may be the outcome of the low diversity of the original population used in the control breeding, the homozygous genotype of the parental used in the beginning of the breeding program, genetic drift during the breeding research, or the occurrence of apomixis.

The loci used in this study showed a medium to high number of alleles in researchs by Chavarriaga-Aguirre et al. (1998) (5 to 15) and Elias et al. (2001) (4 to 9 alleles). The battery of loci used displayed a medium power of individual distinction, shown by the probability of genetic identity. This may be the result of the breeding design, resulting in a maximum value of $1.56527 .10^{-5}$ and $1.711202 .10^{-6}$.

The meiotic study of clone 307 individuals showed $2 n=38$ (Figure 2). Chromosome configurations exhibited 36 bivalents and 2 trivalents in all 20 metaphases examined. Sterility was as high as $92 \%$ judged by pollen grain stainability.

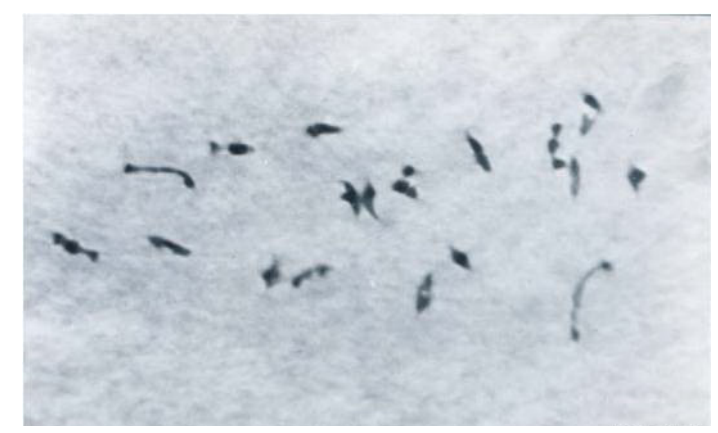

Figure 2. Meiotic metaphase $\mathrm{I}$ in the apomictic clone 307 shows $2 \mathrm{n}=38 ; 16$ bivalents and 2 trivalents. 
The histological study revealed the formation of aposporic embryos in all ovules examined. This apospory led to the formation of embryos in unpollinated ovules. About $23 \%$ of the 90 ovules examined had 2 or 3 embryos (Figure 3).

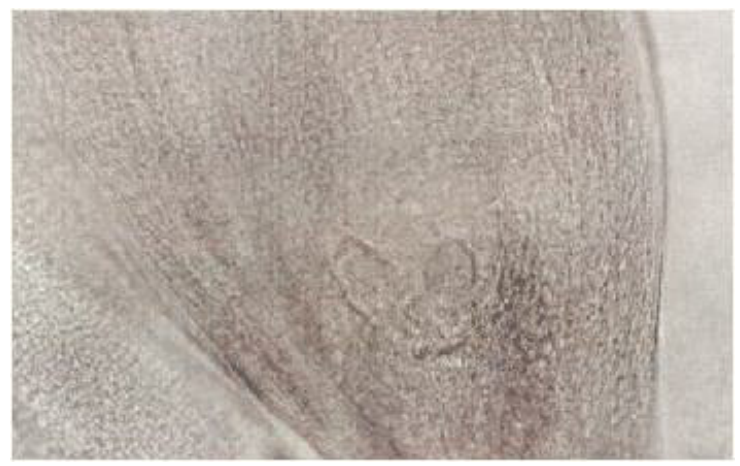

Figure 3. Multiembryonic apospory sac in the spomictic clone 307.

The genetic uniformity of M. glaziovii and its progeny detected by microsatellite segregation showed the apomictic nature of the maternal plant. It seems that apomixis has played an important role in the whole Manihot genus speciation (Nassar, 2003a,b; Nassar and Collevatti, 2005). Apparently, polyploidy has provided a wide genetic variability in the genus, and apomixis has maintained the genotypes that may have been favored in certain niches (Nassar, 2004). Facultative apomixis may then keep the genetic variability through sexual reproduction. These new genotypes may undergo another cycle of speciation in new environmental conditions. Rogers and Appan (1973) defined seven species in the subgenus Glazioviannae to which $M$. glaziovii belongs. The differences among these species are very narrow and limited to size of inflorescences, petiole attachment and bracteole width. These species do hybridize in our living collection creating intermediate types.

The identical genotype of plant 307 and its progeny confirms their apomictic nature. The fact that all sibs investigated may be the outcome of apomixis shows the high level of apomixis reached in this clone. The first author documented apomixis in the progeny of cassava hybrids with $M$. dichotoma (Nassar, 1995; Nassar et al., 1998) and in cassava hybrids with M. neusana (Nassar et al., 2000; Nassar, 2001), but it was detected only in less than 1\% of the progeny, confirmed by the RAPD technique. In further study of the same author, plants could be selected for a higher level of apomixis reaching 13\% (Nassar et al., 2000). This is the first report where apomixis is as high as almost $100 \%$. Apomixis was identified anatomically by the occurrence of one or more embryos in ovules of plants protected against pollination (Figure 3). Genes controlling different levels of apomixis have been found in wild relatives of cultivated crops such as in Panicum maximum (Warmke, 1954). Several F2 genotypes, which resulted from interspecific hybridization of cassava with wild relatives in our living collection, have shown strong evidence of apomixis and abundant fruitfulness accompanied by sterility judged by pollen stainabilty using acetocarmin. It is clear that recurrent selection has resulted in a very significant increase in the level of apomixis to the point of making the present clone practical for use in cassava production, particularly because of its high root productivity, which reaches 6-7 kg per plant. 
Some authors have questioned if obligate apomixis exists (Asker, 1979), but certainly, a very high level of apomixis has been demonstrated in this study. The presence of apomixis in the first generation of hybridization and its absence in the following two generations, when plants were allowed to open-pollinate, shows clearly two genetic facts with respect to apomixis inheritance in cassava: first, apomixis is determined by recessive alleles; second, it is controlled by more than one pair of genes, probably located on different chromosomes. One of the most important consequences of our results is the possibility of mapping and characterizing apomixis genes by molecular markers and isolating them in the future.

\section{ACKNOWLEDGMENTS}

Research partially supported by the National Council for Scientific and Technological Development (CNPq), Brasília, and Universidade Católica de Brasília. Special thanks to the International Development Research Center (IDRC), Ottawa, for support in establishing the living Manihot collection at the Universidade de Brasília in the 1970s, and to Dina Marcia Menezes Ferraz for her help in laboratory work.

\section{REFERENCES}

Asker S (1979). Progress in apomixis research. Hereditas 91: 231-240.

Bassam BJ, Caetano-Anolles G and Gresshoff PM (1991). Fast and sensitive silver staining of DNA in polyacrylamide gels. Anal. Biochem. 196: 80-83.

Bekkaoui F, Mann B and Schroeder B (2003). Application of DNA markers for the identification and management of hybrid poplar accessions. Agroforest Syst. 59: 53-59.

Chavarriaga-Aguirre P, Maya MM, Bonierbale MW, Kresovich S, et al. (1998). Microsatellites in cassava (Manihot esculenta Crantz): discovery, inheritance and variability. Theor. Appl. Genet. 97: 493-501.

Dayanandan S, Rajora OP and Bawa KS (1998). Isolation and characterization of microsatellites in trembling aspen (Populus tremuloides). Theor. Appl. Genet. 96: 950-956.

Doyle JJ and Doyle JL (1990). Isolation of plant DNA from fresh tissue. Focus 12: 13-15.

Elias M, Penet L, Vindry P, McKey D, et al. (2001). Unmanaged sexual reproduction and the dynamics of genetic diversity of a vegetatively propagated crop plant, cassava (Manihot esculenta Crantz), in a traditional farming system. Mol. Ecol. 10: 1895-1907.

FAO (2001). Production Yearbook, Rome.

James CM, Wilson F, Hadonou AM and Tobutt KR (2003). Isolation and characterization of polymorphic microsatellites in diploid strawberry (Fragaria vesca L.) for mapping, diversity studies and clone identification. Mol. Ecol. Notes 3: 171-173.

Marshall TC, Slate J, Kruuk LE and Pemberton JM (1998). Statistical confidence for likelihood-based paternity inference in natural populations. Mol. Ecol. 7: 639-655.

Morgante M and Olivieri AM (1993). PCR-amplified microsatellites as markers in plant genetics. Plant J. 3: 175-182.

Nassar NMA (1995). Development and selection for apomixis in cassava, Manihot esculenta Crantz. Can. J. Plant Sci. 74: 857-858.

Nassar NM (2001). The nature of apomixis in cassava (Manihot esculentum, Crantz). Hereditas 134: 185-187.

Nassar NMA (2003a). Is apomixis in cassava (Manihot esculenta, Crantz) associated with aneuploidy? Gene Conserve 2: $106-110$.

Nassar NM (2003b). Gene flow between cassava, Manihot esculenta Crantz, and wild relatives. Genet. Mol. Res. 2: 334-347. Nassar NMA (2004). Cassava: some ecological and physiological aspects related to plant breeding. Gene Conserve 3: 229-245. Nassar NMA (2007). Wild cassava, Manihot spp. to improve the crop. Gene Conserve 6: 387-414.

Nassar NM and Collevatti RG (2005). Breeding cassava for apomixis. Genet. Mol. Res. 4: 710-715.

Nassar NMA, Vieira MA, Vieira C and Grattapaglia D (1998). Molecular and embryonic evidence of apomixis in cassava interspecific hybrids (Manihot spp.). Can. J. Plant Sci. 78: 349-352.

Nassar NMA, Santos E and David SRO (2000). The transference of apomixis genes from Manihot neusana Nassar to Cassava, M. esculenta Crantz. Hereditas 132: 167-170. 
Nassar NMA, Hashimoto D and Castilho AP (2008). Apomixis induces new species of Manihot. Gene Conserve 7: 636-642. Nei M (1978). Estimation of average heterozygosity and genetic distance from a small number of individuals. Genetics 89: 583-590.

Paetkau D, Calvert W, Stirling I and Strobeck C (1995). Microsatellite analysis of population structure in Canadian polar bears. Mol. Ecol. 4: 347-354.

Rogers D and Appan SG (1973). Manihot, Manihotoids. Flora Neotropica, Hafner Press, New York.

Stenberg P, Lundmark M and Saura A (2003). MLGsim: a program for detecting clones using a simulation approach. Mol. Ecol. Notes 3: 329-331.

Vignani R, Scali M, Masi E and Cresti M (2002). Genomic variability in Vitis vinifera L. "Sangiovese" assessed by microsatellite and non-radioactive AFLP test. Electron. J. Biotechnol. 5: 1-11.

Warmke HE (1954). Apomixis in Panicum maximum. Am. J. Bot. 41: 5-10.

Wyman J, Bruneau A and Tremblay MF (2003). Microsatellite analysis of genetic diversity in four populations of Populus tremuloides in Quebec. Can. J. Bot. 81: 360-367.

Young BA, Sherwood RT and Bashaw EC (1979). Cleared-pistil and thick sectioning techniques for detecting aposporous apomixis in grasses. Can. J. Bot. 57: 1668-1672.

\section{APPENDIX}

\section{Description of clone 307}

The plant is $2 \mathrm{~m}$ in height, roots from seed are swollen (not a tap root), the shape is ovate with $20-30 \mathrm{~cm}$, color is dark brown, stipule scars raised and prominent. Leaves are palmately lobed with seven lobes. Leaves lobe obovate with $8-10 \mathrm{~cm}$; its margins are entire, petioles about $15 \mathrm{~cm}$, attached basally to the lamina, frequently 5-lobed, lamina dark green with red petioles, petioles $10 \mathrm{~cm}$ long, young foliage at stem apices green. Inflorescence a panicle about $6 \mathrm{~cm}$ long, bracts and bracteoles are caduceus. Pistillate flowers green, staminate flowers green with stamins almost sterile having $10 \%$ pollen viability measured by carmin stain. Fruit winged, dark green. Seeds are caranculate and elongate and light brown in color. 